www.nature.com/ja

\title{
JBIR-31, a new teleocidin analog, produced by salt-requiring Streptomyces sp. NBRC 105896 isolated from a marine sponge
}

\author{
Miho Izumikawa ${ }^{1,4}$, Shams Tabrez Khan ${ }^{1,4}$, Hisayuki Komaki ${ }^{1,2}$, Motoki Takagi ${ }^{1}$ and Kazuo Shin-ya ${ }^{3}$
}

The Journal of Antibiotics (2010) 63, 33-36; doi:10.1038/ja.2009.113; published online 20 November 2009

Keywords: cytotoxicity; Haliclona sp.; marine sponge; Streptomyces; teleocidin

The marine environment has recently been described as a source of novel chemical diversity for drug discovery, ${ }^{1}$ as many bioactive substances are isolated from marine organisms including phytoplankton, algae, sponges, tunicates and mollusks. ${ }^{2,3}$ Our group has also reported the isolation of azaspiracid- $2^{4}$ and JBIR- $44^{5}$ from marine sponges. Microorganisms from marine habitats, ${ }^{6,7}$ especially actinobacteria, also constitute a promising untapped resource of novel compounds and are receiving special attention. Compared with higher organisms, microorganisms can be easily maintained under laboratory conditions ensuring a constant and inexpensive supply of their secondary metabolites. Moreover, compounds originally thought to be produced by a marine organism were later found to be produced by hostassociated microorganisms. ${ }^{8}$ A significant body of work has emerged in the past 10 years on the isolation of actinobacteria from marine habitats and their screening has yielded several novel bioactive compounds. $^{9-11}$

Our group recently engaged in the isolation of microorganisms from marine sources including fungi and actinobacteria. Some of the isolated fungi were found to produce novel compounds, namely, JBIR27, $-28,{ }^{12}-15,{ }^{13}-37$ and $-38 .{ }^{14}$ Among actinobacteria, many novel members of the genus Streptomyces were isolated from a marine sponge Haliclona sp. ${ }^{15}$ Interestingly, many of the isolated strains required salt for their optimal growth. The requirement of salt by these strains may indicate their marine origin. One such salt-requiring strain Streptomyces sp. NBRC 105896 was isolated from Haliclona sp. When tested for the production of novel secondary metabolites, Streptomyces sp. NBRC 105896 produced a novel teleocidin analog designated as JBIR-31 (1) with eight known compounds. This paper describes the fermentation, isolation, structure elucidation and briefly the biological activity of $\mathbf{1}$.

To isolate Streptomyces sp. NBRC 105896 from Haliclona sp. collected from the sea shore at Tateyama, Chiba Prefecture, Japan, starch casein nitrate $(\mathrm{SCN})$ agar $^{16}$ was used. A colony that appeared on SCN plates was selected and was further purified using ISP-2 medium ${ }^{17}$ prepared in $50 \%(\mathrm{v} / \mathrm{v})$ artificial seawater (Sealife, Marinetech, Tokyo, Japan). Interestingly, NBRC 105896 required 50-75\% $(\mathrm{v} / \mathrm{v})$ seawater for optimal growth and the growth in the absence of sea salts was very weak. A comparison of partial 16S rRNA sequences (AB498723) for NBRC 105896 with the DNA Data Bank of Japan database (http://www.ddbj.nig.ac.jp/) showed that this strain shared a $100 \% 16 \mathrm{~S}$ rRNA sequence similarity with strain Streptomyces sp. TP-A0873 (AB449972). The closest validly published species was Streptomyces bambergiensis (EF654096), with only 98\% sequence similarity. Marine actinobacteria are a preeminent source of novel secondary metabolites, but their existence per se was questionable. Recently, not only has their existence been confirmed by the isolation of obligate marine actinobacteria ${ }^{18}$ by showing their presence in the deepest marine environment ${ }^{19}$ but they have also been shown to produce a number of novel metabolites. ${ }^{6,7,9-11}$ A character that differentiates marine actinobacteria from terrestrial bacteria is the requirement of salt. During this study, a salt-requiring strain of Streptomyces sp. NBRC 105896 isolated from a marine sponge Haliclona sp. may be considered as indigenous to the marine habitat.

To examine for the production of secondary metabolites by the strain NBRC 105896, the strain was cultivated in 500-ml Erlenmeyer

${ }^{1}$ Biomedicinal Information Research Center, Japan Biological Informatics Consortium, 2-4-7 Aomi, Koto-ku, Tokyo, Japan; ${ }^{2}$ NITE Biological Resource Center, National Institute of Technology and Evaluation, 2-5-8 Kazusakamatari, Kisarazu, Chiba, Japan and ${ }^{3}$ Biomedicinal Information Research Center, National Institute of Advanced Industrial Science and Technology, 2-4-7 Aomi, Koto-ku, Tokyo, Japan

${ }^{4}$ These authors contributed equally to this work

Correspondence: Dr M Takagi, Biomedicinal Information Research Center, Japan Biological Informatics Consortium, 2-4-7 Aomi, Koto-ku, Tokyo 135-0064, Japan.

E-mail: motoki-takagi@aist.go.jp or Dr K Shin-ya, Biomedicinal Information Research Center, National Institute of Advanced Industrial Science and Technology, 2-4-7 Aomi, Koto-ku, Tokyo 135-0064, Japan.

E-mail: k-shinya@aist.go.jp

Received 6 August 2009; revised 30 September 2009; accepted 29 October 2009; published online 20 November 2009 
flasks containing $100 \mathrm{ml}$ of the production medium containing $2.5 \%$ starch (Kosokagaku, Tokyo, Japan), 1.5\% soybean meal (Nisshin Oillio, Tokyo, Japan), $0.2 \%$ dry yeast (Mitsubishi Tanabe Pharma, Osaka, Japan), $0.4 \% \mathrm{CaCO}_{3}$ (Kozaki Pharmaceutical, Tokyo, Japan) and $1.75 \%$ Sealife ( $\mathrm{pH} 6.2$ before sterilization), and cultured on a rotary shaker (180 r.p.m.) at $27^{\circ} \mathrm{C}$ for 5 days. The structures of secondary metabolites by NBRC 105896 were determined by HRelectrospray ionization-MS and UV spectroscopic data. Interestingly, a total of nine compounds, including a novel compound $\mathbf{1}$, were purified from the culture of NBRC 105896. These include indolactam $\mathrm{V},{ }^{20}$ mocimycin, ${ }^{21}$ 5,6-dihydromocimycin, ${ }^{22} \mathrm{~N}$-demethylteleocidin $\mathrm{A}_{1},{ }^{23} \mathbf{1}$ and teleocidin $\mathrm{A}_{1}{ }^{24}$ from the mycelial extract, and factumycin ${ }^{25}$ and kirrothricin ${ }^{22}$ from the supernatant extract of the culture. Levorin $\mathrm{A}_{2}{ }^{26}$ was also detected in the culture grown in a production medium containing 1\% HP-20 (Mitsubishi Chemical, Tokyo, Japan).

To isolate a novel compound $\mathbf{1}$, the fermentation broth $(1000 \mathrm{ml})$ was centrifuged, and the collected mycelial cake was extracted with acetone $(250 \mathrm{ml})$. The extract was concentrated in vacuo, and the residual aqueous concentrate was extracted with EtOAc and evaporated to dryness. The dried residue $(507 \mathrm{mg})$ was subjected to normal- phase medium-pressure liquid chromatography (Purif-Pack SI-60, Moritex, Tokyo, Japan) using an $n$-hexane-EtOAc linear gradient system (0-10\% EtOAc), followed by a chloroform-MeOH linear gradient system $(0-20 \% \mathrm{MeOH})$. The fractions including 1 were collected by LC-MS monitoring. The eluate (2-5\% MeOH, $8.9 \mathrm{mg})$ was subjected to preparative reversed-phase HPLC using a PEGASILODS column (20 i.d. $\times 150 \mathrm{~mm}$; Senshu Scientific, Tokyo, Japan) developed using $75 \%$ aqueous $\mathrm{MeOH}$ containing $0.125 \%$ formic acid (flow rate, $10 \mathrm{ml} \mathrm{min}^{-1}$ ) to yield teleocidin $\mathrm{A}_{1}(0.7 \mathrm{mg}$, retention time $(\mathrm{Rt})=10.3 \mathrm{~min})$ and JBIR-31 (1, $0.8 \mathrm{mg}, \mathrm{Rt}=34.2 \mathrm{~min})$.

Compound 1 was obtained as a colorless amorphous solid (melting point, $58-62{ }^{\circ} \mathrm{C}$, optical rotation, $[\alpha]_{\mathrm{D}}{ }^{25}-226.3, c 0.02$, in $\mathrm{MeOH}$ ), and its molecular formula was determined to be $\mathrm{C}_{27} \mathrm{H}_{39} \mathrm{~N}_{3} \mathrm{O}_{3}$ (found: 454.3073 $[\mathrm{M}+\mathrm{H}]^{+}$, calculated: 454.3070$)$ on the basis of HR-electrospray ionization-MS analysis. The presence of an oxindole chromophore was deduced from its UV and IR spectra $\left(\lambda_{\max }(\mathrm{MeOH}) 243\right.$ $(\varepsilon=12490), 309(\varepsilon=1600) \mathrm{nm}$ and $\left.v_{\max }(\mathrm{KBr}) 1709 \mathrm{~cm}^{-1}\right)$. The structure of 1 was mainly determined by NMR spectral analyses and the tabulated ${ }^{13} \mathrm{C}$ and ${ }^{1} \mathrm{H}$ NMR spectral data for $\mathbf{1}$ are shown in Table 1. A comparison of the ${ }^{13} \mathrm{C}$ and ${ }^{1} \mathrm{H}$ NMR data of 1 with those of

Table $1{ }^{13} \mathrm{C}(150 \mathrm{MHz})$ and ${ }^{1} \mathrm{H}(600 \mathrm{MHz}) \mathrm{NMR}$ data for teleocidin $\mathrm{A}_{1}$ and 1

\begin{tabular}{|c|c|c|c|c|}
\hline \multirow[b]{2}{*}{ No. } & \multicolumn{2}{|c|}{ Teleocidin $A_{1}^{24}$} & \multirow{2}{*}{$\begin{array}{c}1 \\
\delta_{C}\end{array}$} & \multirow[b]{2}{*}{$\delta_{H}$ (multiplicity, $\mathrm{J}=\mathrm{Hz}$ ) } \\
\hline & $\delta_{C}$ & $\delta_{H}$ (multiplicity, $\mathrm{J}=\mathrm{Hz}$ ) & & \\
\hline 1 & & $8.50(\mathrm{br}, \mathrm{s})$ & & 7.79 (s) \\
\hline 2 & 120.7 & $6.81(\mathrm{br}, \mathrm{s})$ & 178.2 & \\
\hline 3 & 121.4 & & 43.6 & $3.90(\mathrm{dd}, 10.9,5.3)$ \\
\hline $3 a$ & 114.1 & & 116.0 & \\
\hline 4 & 146.2 & & 148.4 & \\
\hline 5 & 106.1 & $6.44(d, 8.0)$ & 111.0 & $6.52(\mathrm{~d}, 8.8)$ \\
\hline 6 & 119.7 & $6.96(d, 8.0)$ & 127.2 & $7.09(\mathrm{~d}, 8.8)$ \\
\hline 7 & 118.4 & & 119.5 & \\
\hline $7 a$ & 137.2 & & 140.2 & \\
\hline \multirow[t]{2}{*}{8} & 33.7 & $3.11(\mathrm{dd}, 17.5,2.0)$ & 29.0 & $2.47(\mathrm{~m})$ \\
\hline & & $3.05(d d, 17.5,3.5)$ & & $1.58(\mathrm{~m})$ \\
\hline 9 & 55.7 & $4.32(\mathrm{br}, \mathrm{s})$ & 53.3 & $4.17(\mathrm{~m})$ \\
\hline 10 & & $7.77(\mathrm{br}, \mathrm{s})$ & & $6.31(d, 5.9)$ \\
\hline 11 & 174.7 & & 173.1 & \\
\hline 12 & 70.6 & $4.33(d, 12.0)$ & 67.2 & $4.07(\mathrm{~d}, 8.5)$ \\
\hline \multirow[t]{2}{*}{14} & 64.7 & $3.72(\mathrm{dd}, 11.5,3.0)$ & 65.8 & $3.70(\mathrm{~m})$ \\
\hline & & $3.56(\mathrm{dd}, 11.5,8.5)$ & & $3.53(\mathrm{~m})$ \\
\hline 15 & 28.1 & $2.55(\mathrm{~m})$ & 29.7 & $2.48(\mathrm{~m})$ \\
\hline 16 & 21.5 & $0.89(d, 6.5)$ & 21.1 & $1.03(\mathrm{~d}, 6.5)$ \\
\hline 17 & 19.3 & $0.62(d, 6.5)$ & 19.4 & $0.80(d, 6.8)$ \\
\hline 18 & 32.9 & $2.87(\mathrm{~s})$ & 33.5 & $2.86(\mathrm{~s})$ \\
\hline 19 & 43.0 & & 42.8 & \\
\hline 20 & 25.3 & $1.44(\mathrm{~s})$ & 24.4 & $1.35(\mathrm{~s})$ \\
\hline 21 & 148.3 & $6.15(\mathrm{dd}, 18.0,10.0)$ & 146.6 & $6.03(\mathrm{dd}, 17.8,10.6)$ \\
\hline \multirow[t]{2}{*}{22} & 112.1 & $5.30(\mathrm{dd}, 18.0)$ & 113.3 & $5.26(d, 10.6)$ \\
\hline & & $5.26(\mathrm{dd}, 10.0)$ & & $5.22(d, 17.8)$ \\
\hline \multirow[t]{2}{*}{23} & 38.3 & $1.89(\mathrm{td}, 12.0,12.0,3.0)$ & 38.3 & $1.73(\mathrm{~m})$ \\
\hline & & $1.80(\mathrm{td}, 12.0,12.0,3.0)$ & & \\
\hline \multirow[t]{2}{*}{24} & 22.6 & $1.93(\mathrm{br}, \mathrm{m})$ & 22.8 & $1.90(\mathrm{~m})$ \\
\hline & & $1.70(\mathrm{br}, \mathrm{m})$ & & $1.72(\mathrm{~m})$ \\
\hline 25 & 124.4 & $5.06(\mathrm{br}, \mathrm{m})$ & 123.9 & $5.07(t, 6.8)$ \\
\hline 26 & 131.3 & & 131.6 & \\
\hline 27 & 23.6 & $1.47(\mathrm{br}, \mathrm{s})$ & 25.5 & $1.65(\mathrm{~s})$ \\
\hline 28 & 17.2 & $1.63(\mathrm{br}, \mathrm{s})$ & 17.3 & $1.49(\mathrm{~s})$ \\
\hline
\end{tabular}

NMR spectra were obtained using the Varian NMR system $600 \mathrm{NB} C L$ (Palo Alto, CA, USA) in MeOH- $d_{4}\left(\mathrm{CD}_{3} \mathrm{OD}\right)$, and the solvent peak was used as an internal standard $\left(\delta_{\mathrm{H}} 3.35\right.$ and $\delta_{\mathrm{C}} 49.0$ p.p.m.). 


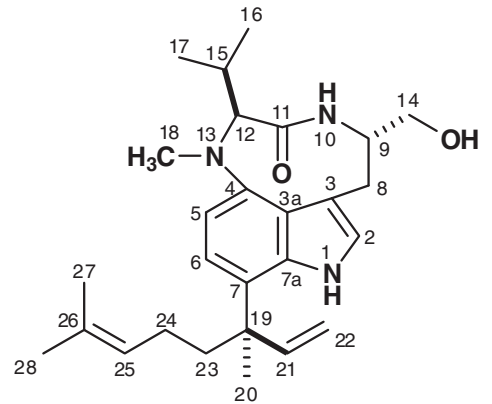

teleocidin $\mathrm{A}_{1}$

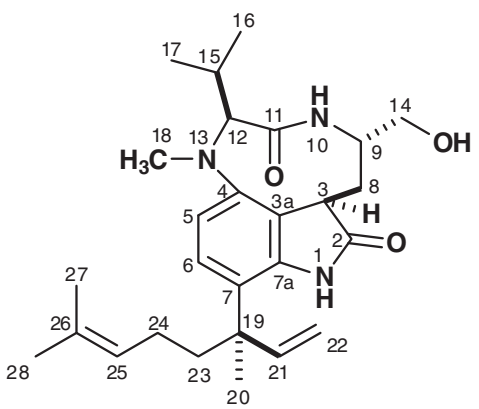

2-oxo-teleocidin $A_{1}$ (JBIR-31, 1)

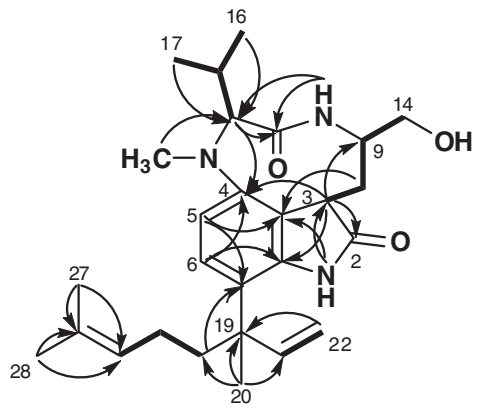

20

Figure 1 Structures of teleocidin $A_{1}$ and JBIR-31 (1), and key correlations in the double quantum-filtered correlation spectroscopy (bold line) and heteronuclear multiple bond coherence (arrow) spectra of 1 .

teleocidin $\mathrm{A}_{1}$, together with $2 \mathrm{D}$ NMR spectral analyses such as ${ }^{1} \mathrm{H}-{ }^{1} \mathrm{H}$ double quantum-filtered correlation spectroscopy and heteronuclear multiple bond coherence spectra, the key correlations of which are summarized in Figure 1, revealed that $\mathbf{1}$ consisted of a skeleton similar to that of teleocidin $A_{1}$. In the ${ }^{1} \mathrm{H}$ NMR spectrum of 1 , all proton signals that are observed in teleocidin $\mathrm{A}_{1}$, except for an olefinic proton $2-\mathrm{H}$, were observed; moreover, a methine proton $3-\mathrm{H}\left(\delta_{\mathrm{H}} 3.90\right)$ was also newly observed. This methine proton was determined to be $3-\mathrm{H}$ in the oxindole ring by the sequence from $3-\mathrm{H}$ to hydroxymethylene protons $14-\mathrm{H}\left(\delta_{\mathrm{H}} 3.70,3.53\right)$ through to methylene protons $8-\mathrm{H}\left(\delta_{\mathrm{H}}\right.$ $2.47,1.58)$ and a methine proton $9-\mathrm{H}\left(\delta_{\mathrm{H}} 4.17\right)$. Furthermore, the ${ }^{13} \mathrm{C}$ NMR spectrum of 1 exhibited a carbonyl carbon C-2 $\left(\delta_{\mathrm{C}} 178.2\right)$ instead of olefinic carbons $\mathrm{C}-2\left(\delta_{\mathrm{C}} 120.7\right)$ and C-3 $\left(\delta_{\mathrm{C}} 121.4\right)$ in teleocidin $\mathrm{A}_{1}$. The ${ }^{1} \mathrm{H}_{-}{ }^{13} \mathrm{C}$ long-range couplings from $3-\mathrm{H}$ to $\mathrm{C}-2, \mathrm{C}-4$ $\left(\delta_{\mathrm{C}} 148.4\right), \mathrm{C}-7 \mathrm{a}\left(\delta_{\mathrm{C}} 140.2\right)$ and $\mathrm{C}-9\left(\delta_{\mathrm{C}} 53.3\right)$ also confirmed the oxindole moiety. From these observations, 1 was deduced to be 2-oxoteleocidin $A_{1}$ (Figure 1). The similarity of ${ }^{1} \mathrm{H}$ NMR signals of 1 to those of teleocidin $A_{1}$ indicated that $\mathbf{1}$ has the same configuration as teleocidin $A_{1}$, except $C-3$. In comparison with the ${ }^{1} \mathrm{H}$ NMR spectrum and an optical rotation of (-)-2-oxo-indlactam $\mathrm{V},{ }^{27}$ the absolute configuration of 1 at C-3 could be $R$ (Figure 1). Although the 2-oxo teleocidin derivatives of (-)-indolactam $\mathrm{V}^{20}$ such as (-)-2-oxoindolactam $\mathrm{V},{ }^{27}$ and blastmycetin $\mathrm{B}$ and $\mathrm{C}^{28,29}$ have already reported, $\mathbf{1}$ is the first 2-oxo derivative of teleocidin.

Cytotoxic activities of $\mathbf{1}$ against human cervical carcinoma HeLa cells and human malignant pleural mesothelioma (MPM) ACC-MESO-1 cells ${ }^{30,31}$ were tested by WST-8 (2-(2-methoxy-4-nitrophenyl)-3-(4-nitrophenyl)-5-(2,4-disulfophenyl)-2H-tetrazolium, monosodium salt) colorimetric assay (Cell Counting Kit, Dojindo, Kumamoto, Japan). As a result, 1 and teleocidin $\mathrm{A}_{1}$ showed cytotoxic effects against HeLa ( $\mathrm{IC}_{50}=49$ and $35 \mu \mathrm{M}$, respectively) and ACCMESO- $1\left(\mathrm{IC}_{50}=88\right.$ and $\left.11 \mu \mathrm{M}\right)$ cells for $48 \mathrm{~h}$. Although the cytotoxic activities of these compounds were weak, these compounds showed cytotoxic effects for MPM cells that confer resistance to clinical anticancer drugs. It is therefore interesting to study the mechanism of cytotoxicity of 1 and teleocidin $A_{1}$. Teleocidin is a potent tumor promoter on mouse skin and activates protein kinase $\mathrm{C}$, which has crucial roles in the signal-transduction pathways affecting a variety of physiological activities. ${ }^{32}$ Recently, it has been reported that a teleocidin derivative, $14-\mathrm{O}$-( $\mathrm{N}$-acetylglucosaminyl) teleocidin $\mathrm{A}$, induces the translocation of protein kinases $\mathrm{C} \alpha$ and $\theta$, and sensitizes the release of excitatory neuropeptide substance $\mathrm{P}$ induced by capsaicin from primary-cultured dorsal root ganglion neurons of the rat. ${ }^{33}$ Because teleocidin analogs possess various biological activities, studies on detailed biological activities against MPM cells by $\mathbf{1}$ and teleocidin $A_{1}$ are now underway.

In conclusion, we found that the strain Streptomyces sp. NBRC 105896 produces several secondary metabolites including a novel teleocidin analog. Results presented in this paper and those of previous studies contributed by our group ${ }^{12-14}$ strongly suggest that marine microorganisms are a promising source of novel secondary metabolites.

\section{ACKNOWLEDGEMENTS}

This study was supported by a grant from the New Energy and Industrial Technology Department Organization (NEDO) of Japan. We thank Takeshi Fujiwara of OP BIO FACTORY for his help in collecting the sponge sample.

1 Ward, A. C. \& Bora, N. Diversity and biogeography of marine actinobacteria. Curr. Opin. Microbiol. 9, 279-286 (2006).

2 Faulkner, D. J. Marine natural products. Nat. Prod. Rep. 19, 1-48 (2002).

3 Zhang, L. et al. Exploring novel bioactive compounds from marine microbes. Curr. Opin. Microbiol. 8, 276-281 (2005).

4 Ueoka, R. et al. Isolation of azaspiracid-2 from a marine sponge Echinoclathria sp. as a potent cytotoxin. Toxicon 62, 159-162 (2009).

5 Fujiwara, T. et al. JBIR-44, a new bromotyrosine compound from a marine sponge Psammaplysilla purpurea. J. Antibiot. 62, 393-395 (2009).

6 Wagner-Döbler, I., Biel, W., Lang, S., Meiners, M. \& Laatsch, H. Integrated approach to explore the potential of marine microorganisms for the production of bioactive metabolites. Adv. Biochem. Engin./Biotechnol. 74, 208-238 (2002).

7 Blunt, J. W. et al. Marine natural products. Nat. Prod. Rep. 25, 35-94 (2008).

$8 \mathrm{Wu}, \mathrm{Z}$. et al. A new tetrodotoxin-producing actinomycete, Nocardiopsis dassonvillei, isolated from the ovaries of pufferfish Fugu rubripes. Toxicon 45, 851-859 (2005).

9 Fenical, W. \& Jensen, P. R. Developing a new resource for drug discovery: marine actinomycete bacteria. Nat. Chem. Biol. 2, 666-673 (2006).

10 Lam, K. S. Discovery of novel metabolites from marine actinomycetes. Curr. Opin. Microbiol. 9, 245-251 (2006).

11 Newman, D. J. \& Hill, R. T. New drugs from marine microbes: the tide is turning. J. Ind. Microbiol. Biotechnol. 33, 539-544 (2006).

12 Motohashi, K. et al. New sesquiterpenes, JBIR-27 and -28, isolated from a tunicate-derived fungus, Penicillium sp. SS080624SCf1. J. Antibiot. 62, 283-285 (2009).

13 Motohashi, K., Inaba, S., Takagi, M. \& Shin-Ya, K. JBIR-15, a new aspochracin derivative, isolated from a sponge-derived fungus, Aspergillus sclerotiorum Huber Sp080903f04. Biosci. Biotechnol. Biochem. 73, 1898-1900 (2009).

14 Izumikawa, M. et al. JBIR-37 and -38, novel glycosyl benzenediols, isolated from a sponge-derived fungus, Acremonium sp. SpF080624G1f01. Biosci. Biotechnol. Biochem. 73, 2138-2140 (2009).

15 Khan, S. T., Tamura, T., Takagi, M. \& Shin-ya, K. Streptomyces tateyamaensis sp. nov., Streptomyces marinus sp. nov. and Streptomyces haliclonae sp. nov., three novel species of Streptomyces isolated from marine sponge Haliclona sp. Int. J. Syst. Evol. Microbiol. (in submission).

16 Shirling, E. B. \& Gottlieb, D. Methods for characterization of Streptomyces species. Int. J. Syst. Bacteriol. 16, 313-340 (1966).

17 Küster, E. \& Williams, S. T. Selective media for isolation of Streptomycetes. Nature 202, 928-929 (1964). 
18 Mincer, T. J., Jensen, P. R., Kauffman, C. A. \& Fenical, W. Widespread and persistent populations of a major new marine actinobacteria taxon in ocean sediments. Appl. Environ. Microbiol. 68, 5005-5011 (2002).

19 Pathom-aree, W. et al. Diversity of actinomycetes isolated from the challenger deep sediment (10,898 m) from the Mariana Trench. Extremophiles 10, 181-189 (2006).

20 Irie, K. et al. The Epstein-barr virus early antigen inducing indole alkaloids, (-)-indolactam $V$ and its related compounds, produced by actinomycetes. Agric. Biol. Chem. 48, 1269-1274 (1984).

21 Maehr, H., Leach, M., Yarmchuk, L. \& Stempel, A. Antibiotic X-5108. V. Structures of antibiotic X-5108 and mocimycin. J. Am. Chem. Soc. 95, 8449-8450 (1973).

22 Maehr, H., Leach, M., Williams, T. H. \& Blount, J. F. The chemistry of aurodox and related antibiotics. Can. J. Chem. 58, 501-526 (1980).

23 Irie, K. et al. Isolation and biological activities of $N^{13}$-desmethyl analogues of tumor promoter teleocidin from Streptoverticillium blastmyceticum. Agric. Biol. Chem. 52, 3193-3195 (1988).

24 Cardellina II, J. H., Marner, F. J. \& Moore, R. E. Seaweed dermatitis: structure of lyngbyatoxin A. Science 204, 193-195 (1979).

25 Gullo, V. P. et al. Factumycin, a new antibiotic (A40A)-fermentation, isolation and anti-bacterial spectrum. J. Antibiot. 35, 1705-1707 (1982).
26 Tsyganov, V. A. \& lakovleva, E. P. Study of type composition of levorin A. Isolation of heptaenic antibiotics from the levorin A complex. Antibiotiki 14, 387-390 (1969).

27 Hagiwara, N. et al. New teleocidin metabolites from Streptoverticillium blastmyceticum. Agric. Biol. Chem. 49, 2529-2530 (1985).

28 Irie, K. et al. New teleocidin-related metabolites from Streptoverticillium blastmyceticum producing tumor-promoting indole alkaloids. Agric. Biol. Chem. 51, 285-287 (1987).

29 Hagiwara, N. et al. Structure and tumor-promoting activity of new teleocidin-related metabolites (blastmycetins) from Streptoverticillium blastmyceticum. Agric. Biol. Chem. 52, 641-648 (1988).

30 Usami, N. et al. Establishment and characterization of four malignant pleural mesothelioma cell lines from Japanese patients. Cancer Sci. 97, 387-394 (2006).

31 Motohashi, K., Hwang, J. H., Sekido, Y., Takagi, M. \& Shin-ya, K. JBIR-23 and -24, novel anticancer agents from Streptomyces sp. AK-AB27. Org. Lett. 11, 285-288 (2009).

32 Fujiki, H. \& Sugimura, T. New classes of tumor promoters: Teleocidin, aplysiatoxin, and palytoxin. Adv. Cancer Res. 49, 223-264 (1987).

33 Nakae, K. et al. A new teleocidin analog from Streptomyces sp. MM216-87F4 induces substance P release from rat dorsal root ganglion neurons. J. Antibiot. 59, 11-17 (2006). 